\title{
Adventitial Rupture of the Ascending Thoracic Aorta Extended to the Buttock by Thoracic Crushing between Two Tanks at the Thoracic and Cardiovascular Surgery Department at the Besançon CHRU
}

\author{
Abdoulaye Kanté1 ${ }^{*}$, Andrea Perrotti², Bréhima Coulibaly', Mamadou Almamy Keita1, \\ Drissa Traoré1, Siaka Diallo1, Mariam Daou33, Mamadou Diakité4, Babou Bah1, \\ Bréhima Bengaly¹, MoustaphIssa Magané5, Bakary Keita5 , Birama Togola1, \\ Drissa Ouattara ${ }^{1}$, Souleymane Sanogo ${ }^{1}$, Timbely Guidèrè ${ }^{1}$, Nouhom Ongoïba ${ }^{1}$, \\ Harrison Haight ${ }^{2}$, Anne Sophie Lacagne ${ }^{2}$, Julie Ritter ${ }^{2}$, Anne Claire Mogenet ${ }^{2}$, \\ Enrica Dorigo ${ }^{2}$, Camille Durst ${ }^{2}$, Djamel Kaili², François Clement ${ }^{2}$, Sidney Chocron² \\ ${ }^{1}$ Service of General Surgery, CHU Point G, Bamako, Mali \\ ${ }^{2}$ Servicet of Thoracic and Cardiovascular Surgery, University Hospital of Besançon, Besançon, France \\ ${ }^{3}$ Service of Neurology, Gabriel Touré Teaching Hospital, Bamako, Mali \\ ${ }^{4}$ Service of Cardiology, CHU Point G, Faculty of Medicine and Odontostomatology, Bamako, Mali \\ ${ }^{5}$ Service of Anesthesia Service and Resuscitation, CHU Gabriel Touré, Bamako, Mali \\ Email: *kanteim@yahoo.fr
}

How to cite this paper: Kanté, A., Perrotti, A., Coulibaly, B., Keita, M.A., Traoré, D., Diallo, S., Daou, M., Diakité, M., Bah, B., Bengaly, B., Magané, M., Keita, B., Togola, B., Ouattara, D., Sanogo, S., Guidèrè, T., Ongoïba, N., Haight, H., Lacagne, A.S., Ritter, J., Mogenet, A.C., Dorigo, E., Durst, C., Kaili, D., Clement, F. and Chocron, S. (2018) Adventitial Rupture of the Ascending Thoracic Aorta Extended to the Buttock by Thoracic Crushing between Two Tanks at the Thoracic and Cardiovascular Surgery Department at the Besançon CHRU. Open Journal of Thoracic Surgery, 8, 74-78. https://doi.org/10.4236/ojts.2018.84013

Received: October 13, 2018

Accepted: November 24, 2018

Published: November 27, 2018

\begin{abstract}
Traumatic rupture of the ascending aorta is rare. We report the case of a 23-year-old man who suffered a service accident by crushing the thorax between two tanks during army maneuvers that resulted in an adventitial rupture of the ascending thoracic aorta extending to the Crosse. Treatment consisted of replacement of the ascending aorta with a $24 \mathrm{~mm}$ Hemashield straight tube and re-implantation of supra-aortic vessels at the dome of the prosthesis.
\end{abstract}

\section{Keywords}

Traumatic Rupture, Ascending Aorta Extended to Lacrosse, Service Accident

\section{Introduction}

The traumatic rupture of the aorta is a very serious event, occurring in a context of violent trauma with strong deceleration. Its morbidity rate remains high de- 
Copyright $\odot 2018$ by authors and Scientific Research Publishing Inc. This work is licensed under the Creative Commons Attribution International License (CC BY 4.0). http://creativecommons.org/licenses/by/4.0/

\section{Open Access}

spite significant progress [1]. Rupture of the thoracic aorta usually occurs at the level of the isthmus in $90 \%$ of cases, but in rare cases it can be extended from the ascending aorta to the buttock. We must think about it and systematically analyze the thoracic aorta so as not to underestimate the extent of the lesion. We report the case of a 23-year-old man, a victim of an accident of service by crushing of the thorax between two tanks during operations of the army having caused a break under adventicielle of the ascending thoracic aorta spread to the butt.

\section{Observation}

This is a 23-year-old man with no particular background, a volunteer in the army, who suffered a service accident by crushing the thorax between two tanks during army maneuvers.

A thoraco-abdominopelvic CT scan with and without contrast injection revealed a diastasis of $3 \mathrm{~cm}$ at the Louis angle, a sternal fracture associated with a sub-lethal rupture of the ascending aorta with lacrosse (Figure 1). Faced with this post-traumatic rupture of the ascending aorta extending to the buttock, surgical treatment with sternotomy was considered urgently. Per operating the exploration highlighted: a diastasis of $3 \mathrm{~cm}$ at the level of Louis's angle, and a hemo pericardium not compressive; a break under adventicielle of the ascending aorta in the junction enters the ascending aorta intra-pericardial and the ascending aorta extra-pericardial which continued until the level of the aortic butt and isolated the brachio-cephalic arterial trunk and the left primitive carotid.

We performed under deep hypothermia, anterograde cerebral perfusion (Figure 2):

- Complete removal of the entire area with adventitial rupture;

- Section between two ligatures of the venomous venous trunk;

- Isolation of the brachiocephalic arterial trunk and left primary carotid artery;

- A transverse section of the intra-pericardial ascending thoracic aorta above the sinotubular junction, replaced by a $24 \mathrm{~mm}$ Hemashield straight tube whose distal anastomosis with descending thoracic aorta was made by a single overlock of prolene 4/0;

- Re-implantation of supra-aortic vessels at the dome of the prosthesis;

- Proximal anastomosis of the tube on the intra-pericardial ascending aorta by two hemisurits of prolene 4/0;

- Synthesis of the sternal diastasis by two sternum threads passed on both sides in the longitudinal direction to bring the diastasis closer and closure of the sternum by four steel wires.

The total time of the CPB was 292 minutes, the duration of the aortic clamping of 46 , circulatory arrest of 48 minutes and the lowest temperature of $17^{\circ} 5$.

The postoperative course was haemodynamically sequential. However the patient presented in the suites:

o a syndrome of lodges at the level of the left lower limb due to a long operation with cannulas obstructing the femoral artery, which required aponeurotomy of discharge; 


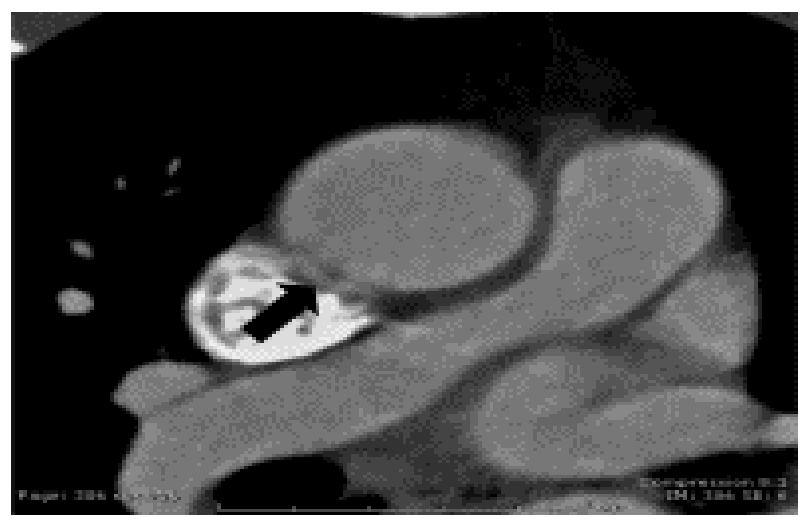

Figure 1. Thoracic CT after injection of the contrast product in axial and sagittal section showing a traumatic aneurism image of $2.2 \mathrm{~cm}$ at the posterior wall of the ascending aorta.



Figure 2. Intraoperative image.

- edema of the left upper limb in relation to ligation of the venomous venous trunk;

○ acute renal failure on rhabdomyolysis;

- a pericardial effusion tamponade with 10 minutes cardiac arrest recovered after evacuation and pericardial drainage;

○ a left partitioned hemothorax removed by thoracotomy; infectious complications in Ecloacae, S. Maltophillia and A. Baumanii.

\section{Discussion}

Traumatic fractures of the aorta are the most frequent lesions of the large vessels of the mediastinum [1]. The only prospective study conducted by Fabian et al [2] showed that approximately $15 \%$ to $23 \%$ of road accident victims die each year from a traumatic rupture of the aorta. A percentage of 80 to 85 died immediately at the scene of the accident, during transportation or emergencies [3] [4].

The mechanisms involved in traumatic lesions of the thoracic aorta are mainly related to deceleration or acceleration resulting in laceration of the wall at the transition zones between a mobile aorta and the aorta is fixed or more rigid [5] 
[6]. Thus, the aortic isthmus is the most frequent location of traumatic rupture of the aorta; it represents $90 \%$ to $98 \%$ in the surgical series and $40 \%$ to $45 \%$ in the autopsy series [7] [8]. The distal descending thoracic aorta is the second location in frequency $7 \%$ to $12 \%$, the ascending thoracic aorta $0 \%$ to $3 \%$. Multiple localizations: isthmus + descending thoracic aorta, isthmus + aortic arch are also possible.

The rupture of the ascending thoracic aorta extended to the aortic arch is exceptional and has not been described in the literature to our knowledge. In this case, our patient had a rupture of the ascending thoracic aorta extended to the butt. The challenge is not to ignore or underestimate this exceptional form of post-traumatic rupture of the thoracic aorta by systematically analyzing the entire aortic axis. The diagnosis of RTA has largely benefited from the generalization of computed tomography (CT). The direct signs of rupture of the aorta whatever the location are: the mediastinal hematoma in continuity with the aorta, the false aneurysm, and the irregularity of the aortic contour, the intimal flap [9]. In our observation we had a champagne cork image at the level of the ascending aorta extended to supra-aortic vessels. Due to the hemodynamic instability at admission, surgical treatment with sternotomy was performed urgently by the placement of an aortic prosthesis (right tube + butt) with reimplantation of the brachiocephalic arterial trunk and left carotid with good evolution on a decline of 10 years.

\section{Conclusion}

The post-traumatic rupture of the ascending thoracic aorta extended to the butt is exceptional but should not be ignored and should be systematically sought. His diagnosis has been improved by advances in radiology, including CT angiography and prognosis, thanks to the speed of transport to specialized hospital facilities and early management.

\section{Conflicts of interest}

We authors of this article declare that there is no conflict of interest.

\section{References}

[1] Sullivan, P.R., Wolfson, A.B., Leckey, R.D. and Burke, J.L. (2000) Diagnostic of Acute Thoracic Aortic Dissection in the Emergency Department. American Journal of Emergency Medicine, 18, 46-50.

[2] Fabian, C., Richardson, J.D., Crocema, M.A., Smith, J.S., Rodman, J.R., Kearney, P.A., et al. (1997) Prospective Study of Blunt Aortic Injury: Multicenter Trial of the American Association for the Surgery of Trauma. The Journal of Trauma: Injury, Infection, and Critical Care, 42, 374-383. https://doi.org/10.1097/00005373-199703000-00003

[3] Freczko, J.D., Lynch, L., Pless, J.E., Clarek, M.A., Mcclain, J. and Hawley, D.A. (1992) An Autopsy Case Review of 142 Nonpenetrating (Blunt) Injuries of the Aorta. The Journal of Trauma: Injury, Infection, and Critical Care, 33, 846-849. 
https://doi.org/10.1097/00005373-199212000-00009

[4] Von Oppeli, U.O., Dune, T.T., De Groot, M.K. and Zilla, P. (1994) Traumatic Aortic Rupture: Twenty-Year Metanalysis of Mortility and Risk of Paraplegia. The Annals of Thoracic Surgery, 58, 585-593.

[5] Richens, D., Field, M., Neale, M. and Oakley, C. (2002) The Mechanism of Injury in Blunt Traumatic Rupture of the Aorta. European Journal of Cardio-Thoracic Surgery, 21, 288-293. https://doi.org/10.1016/S1010-7940(01)01095-8

[6] Blackmore, C.C., Zweibel, A. and Mann, F.A. (2000) Determining Risk of Traumatic Aortic Injury: How to Optimize Imaging Strategy. $A J R, 174,343-347$.

[7] Kodali, S., Jamieson, W.R.E., Leia-Stephens, M., Miyagishima, R.T., Janus, M.T. and Tyers, G.F.O. (1991) Traumatic Rupture of the Thoracic Aorta. A 20 Year Review: 1969-1989. Circulation, 84, III40-III46.

[8] Cowley, R.A., Turney, S.Z., Hankins, J.R., Rodriguez, A., Attar, S. and Shankar, B.S. (1990) Rupture of Thoracic Aorta Caused by Blunt trauma. A Fifteen-Year Experience. The Journal of Thoracic and Cardiovascular Surgery, 100, 652-661.

[9] Tasu, J.P., Kuhi, E., Rocher, L., Miquet, A., Kuoch, V. and Blery, M. (2002) Traumatic Hurts of the Thoracic Aorta: Aspect Semiological and Course to Follow. Journal of Radiology, 42, 19-21. 